\title{
As Finals das Olimpíadas de Química Júnior 2010 em Coimbra
}

No dia 8 de Maio, em Coimbra, decorreram as Finais das Olimpíadas de Química Júnior (OQJr) de 2010. Nesta $3^{a}$ edição das finais para os mais novos - as primeiras na Universidade do Porto e as segundas na Universidade de Lisboa - as OQJr ocorreram em plena Queima das Fitas de Coimbra.

Contaram com 60 participantes, vindos dos 4 cantos do nosso Portugal Continental, apurados dos vencedores nas semifinais (primeiro e segundo classificados) nos Departamentos de Química da Universidade do Minho (Vila Nova de Famalicão e Caldas das Taipas), UTAD (Margaride e Vila Real), Universidade do Porto (Trofa e Póvoa de Varzim), Universidade de Aveiro (Esgueira e Gouveia), Universidade da Beira Interior (Fundão), Universidade de Coimbra (Coimbra e Canas de Senhorim), Instituto Superior Técnico-Lisboa (Restelo-Lisboa, Mem Martins), Universidade Nova de Lisboa (Almada), Universidade de Lisboa (Massamá) e Universidade do Algarve (Montenegro e Faro).

O programa era recheado e muitos dos participantes tiveram de chegar ainda de véspera. Logo de manhã foi grande a azáfama. E também com pequenos percalços, como aconteceu com a escola de Gouveia, que teve um pequeno acidente rodoviário, prontamente resolvido, mas que atrasou a chegada desta escola ao DQ.

Depois da sessão inaugural e de apresentação que contou com o vice-reitor Henrique Madeira e o Director do DQ, Prof. S. J. Formosinho, seguiram-se as provas práticas e teóricas. De acordo com alguns desabafos posteriores, foram "puxadas". Como diria o aluno Paulo Ribeiro da escola de Vila Nova de Famalicão, ao $\mathrm{JN}$, "Correu bem, mas tivemos algumas dificuldades na parte mais avançada da matéria, aquela que estamos a dar agora. (...)".

Mas as provas foram mesmo apelativas e estimulantes como se pode ver de algumas das fotos apresentadas. $E$ enquanto os alunos faziam a sua pro-

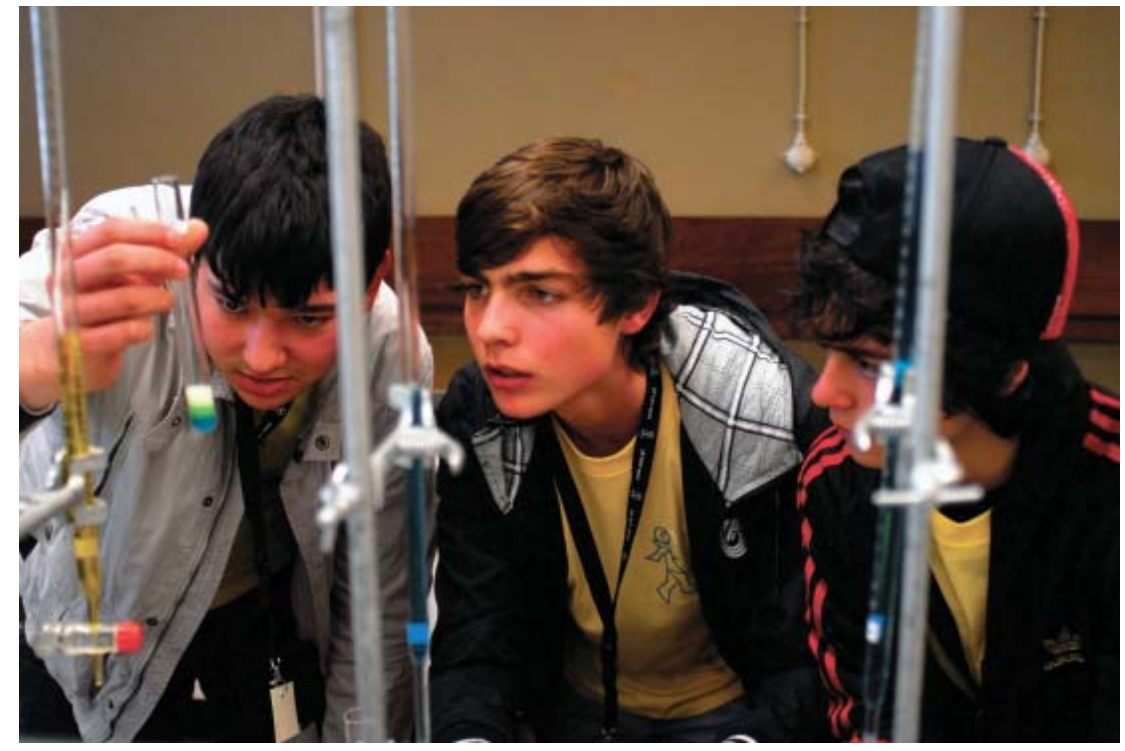

Uma das equipas participantes em plena prova

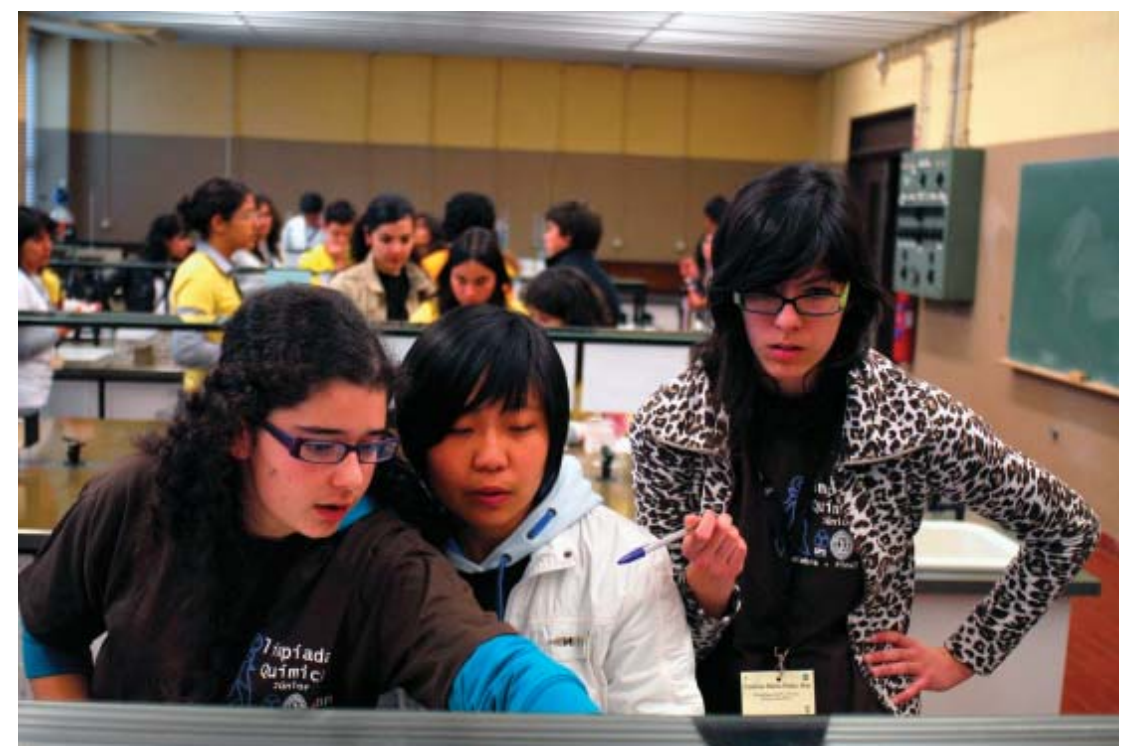

Uma outra equipa participante também em prova

va, os professores foram ao Museu da Ciência da UC e depois seguiram com os "percursos químicos", uma iniciativa do colega Sérgio Rodrigues que visa efectuar "passeios ao encontro de moléculas e materiais que podemos encontrar nas ruas e jardins, nas cidades e no campo". Neste dia o passeio foi feito pela UC, com início no Museu da Ciência. E dentro deste percurso pudemos ver na Biblioteca Joanina uma exposição de livros históricos e raros de Química.

De tarde após um merecido almoço e convívio entre todos, tivemos uma estimulante palestra pelo Prof. Alexande
Costa, o professor que recebeu o Prémio Nacional de Professores deste ano, por sinal um professor de FísicoQuímicas! Foi muito revelador e ficámos todos a saber como se formaram os elementos existentes na Terra existentes na nossa (dos químicos!) Tabela Peródica. O Professor Alexandre Costa contou-nos que durante o Big Bang foram produzidos apenas hidrogénio, hélio e quantidades vestigiais dos elementos mais leves da Tabela Periódica. E que as estrelas, sendo fábricas de produzir elementos, são capazes de produzir elementos até ao Magnésio. Depois, os elementos mais pesados são produzidos na nucleos- 


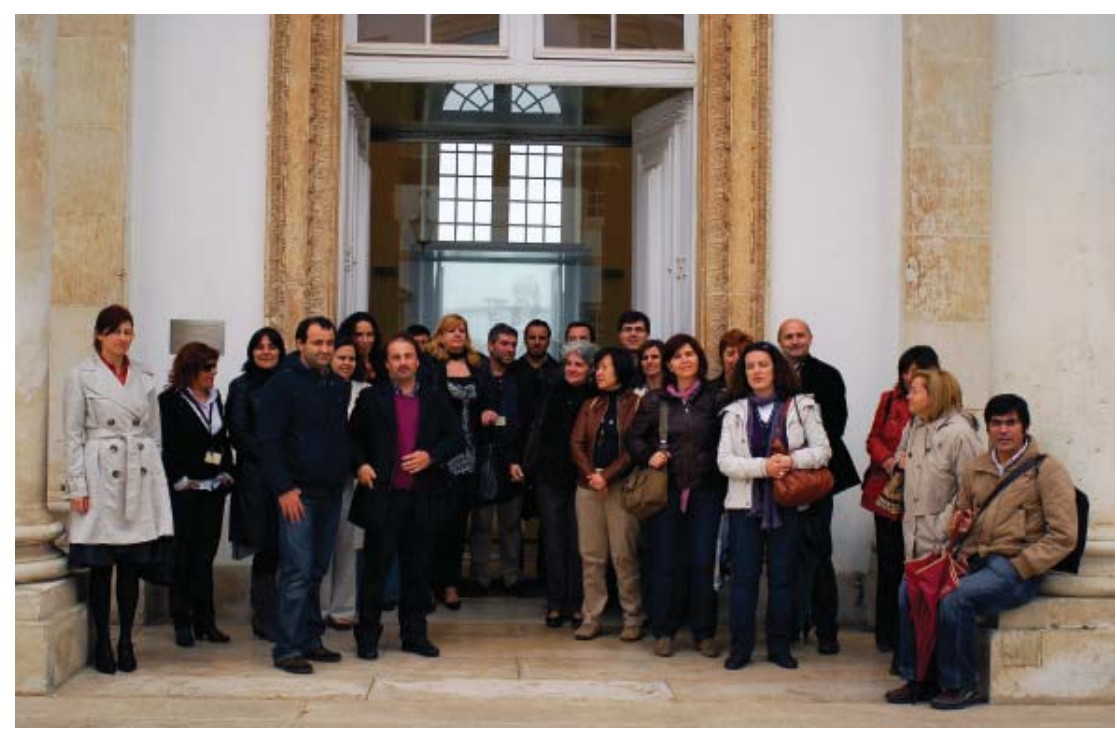

Os professores à porta do Museu da Ciência antes de partirem para os percursos químicos

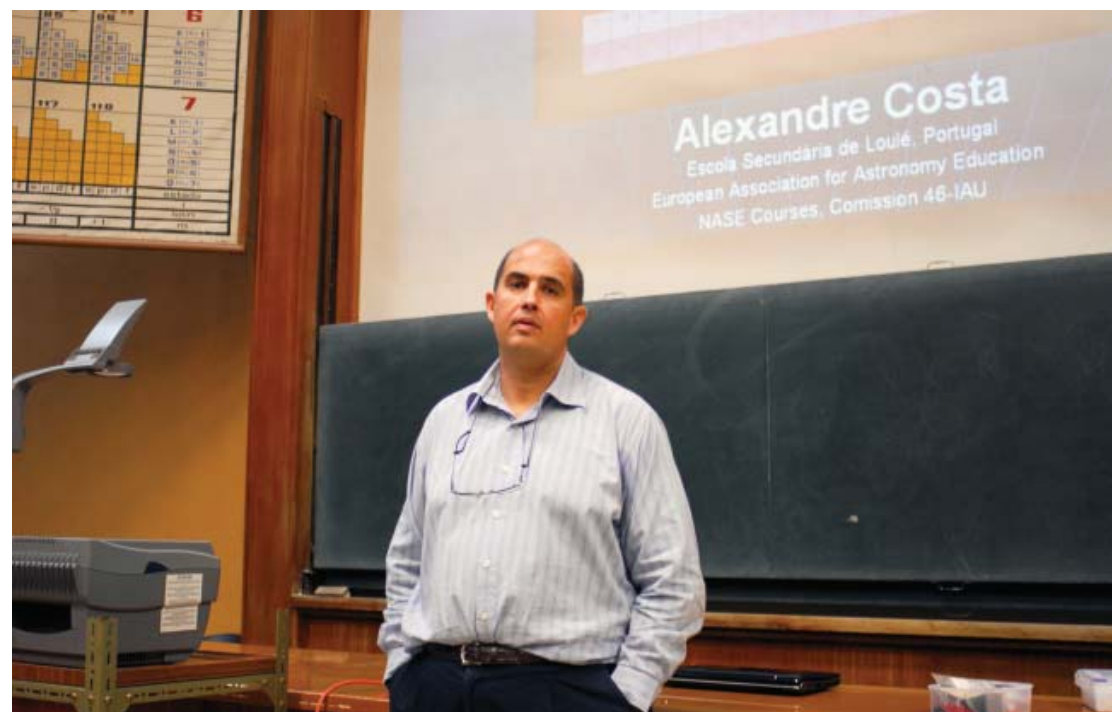

O Prof. Alexandre Costa na apresentação de "Big Bang, evolução estelar e a Tabela Periódica dos elementos"

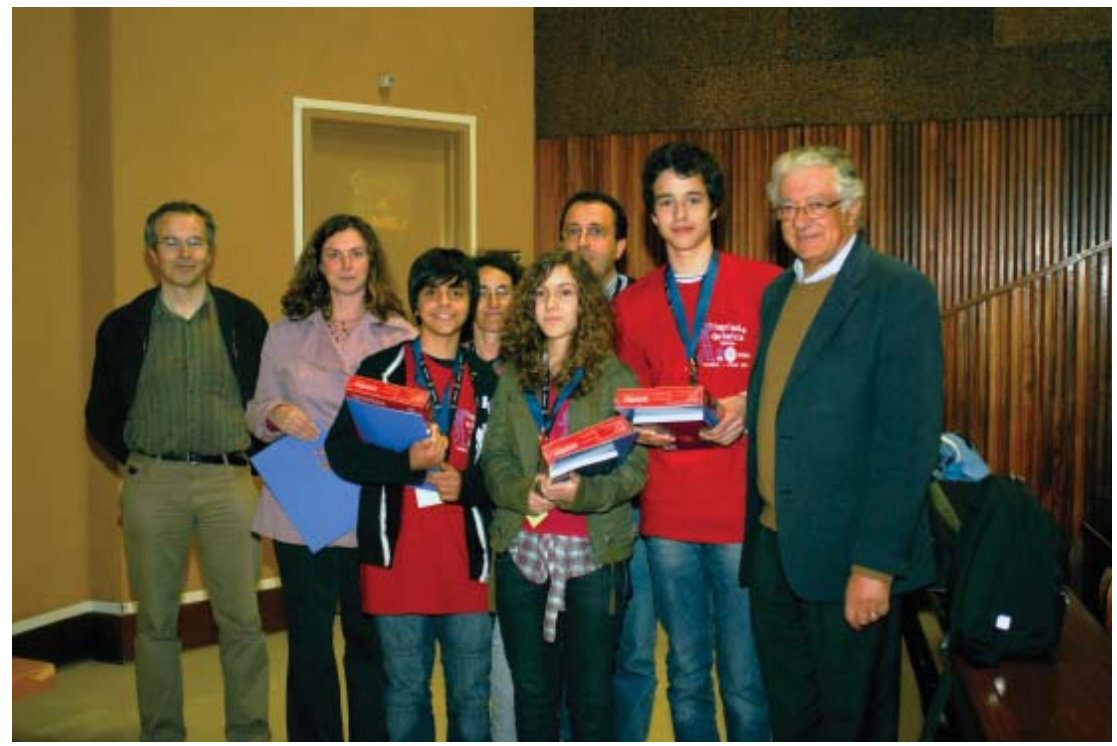

Os vencedores (10 lugar) das finais das Olimpíadas de Química Júnior de 2010, ladeados, à esquerda pelo professor João Gabriel (director da FCTUC) e pela professora Cecília Azevedo e, à direita, pelo Prof. Sebastião Formosinho. Por trás a Prof. ${ }^{a}$ Maria João Moreno e o Prof. Sérgio Seixas de Melo (organizadores) síntese estelar em reacções nucleares que podem, no caso das estrelas mais massivas, chegar até à produção do Ferro-56. A partir deste elemento, devido ao balanço energético envolvido, apenas é possível a produção de elementos mais pesados em supernovas. Esperemos que com esta palestra os nossos alunos tenham sentido a química como uma ciência central e fundamental até para a interpretação do nascimento do Universo!

E terminada a palestra, ainda foi proporcionada, aos alunos, uma ida rápida ao Museu da Ciência. Chegados todos, foi a vez da cerimónia de entrega dos prémios. Uma sessão cheia de suspense pelo resultado final dado que todos acalentavam legítimas expectativas de vitória. Todos os participantes tiveram classificações acima dos $60 \%$, tendo os 3 primeiros classificações acima dos $85 \%$. E os vencedores foram:

$1^{\circ}$ Lugar: Colégio da Trofa, Trofa, com os alunos: Afonso João da Silva, Francisco Amorim e Lígia Dias e com a professora Cecília Azevedo.

$2^{\circ}$ Lugar: Externato Frei Luís de Sousa, Almada, com os alunos: Ana Rita Bello, Francisco António Parente e João Pedro Ferreira e com o professor Miguel Bruno Oliveira.

$3^{\circ}$ Lugar: Escola Básica $2^{\circ}$ e $3^{\circ}$ Ciclos de Eugénio de Castro, de Coimbra, com os alunos: Bernardo da Silva Alves, João Luís Janela, Rita Gomes Teixeira e a professora Isabel Prata.

Os nossos vencedores, o Afonso, o Francisco e a Lígia, irão preparar-se durante o próximo ano para participar nas Olimpíadas de ciências, as EUSO - European Union Science Olympiad cuja nona edição decorrerá em 2011 em Praga. Para eles os nossos votos de muito sucesso. E no final, mesmo a calhar em pleno ambiente de Queima das Fitas, tivemos a Quantunna (a Tuna da FCTUC), a animar o lanche e a despedida.

Aos mini-olímpicos, professores, alunos e colegas da UC; patrocinadores (FCTUC, DQ; BPI, Reitoria, MC, Porto Editora, CMC), o nosso muito obrigado por nos terem proporcinado este dia pleno de animação, convívio e química!. 